\title{
Concentration and Purification of Yacon (Smallanthus sonchifolius) Root Fructooligosaccharides Using Membrane Technology
}

\author{
Maria Julia Ledur Alles ${ }^{1 *}$, Isabel Cristina Tessaro ${ }^{2}$ and Caciano Pelayo Zapata Noreña ${ }^{1}$ \\ ${ }^{1}$ Institute of Food Science and Technology, Federal University of Rio Grande do Sul, \\ Avenida Bento Gonçalves n 9500, Prédio 43212, 91501-970, Porto Alegre, RS, Brazil \\ ${ }^{2}$ Laboratory of Membrane Separation Processes, Chemical Engineering Department, Federal University of \\ Rio Grande do Sul, Rua Engenheiro Luiz Englert, s/nº - Prédio 12204, 90040-040, Porto Alegre, RS, Brazil
}

Received: June 12, 2014

Accepted: March 3, 2015

\begin{abstract}
Summary
Yacon is a perennial plant originating from the Andean region whose roots have been receiving increased attention due to their high content of prebiotic fructooligosaccharides (FOS). Apart from many health benefits, FOS have interesting characteristics as food ingredients, so are used as sugar substitute, and their extraction from yacon roots may be an alternative to commercially available FOS. This work evaluates membrane technology for concentration and purification of FOS from yacon root extract, combining ultrafiltration (UF) with nanofiltration (NF), with and without the use of discontinuous diafiltration (DF). After UF, $63.75 \%$ of the saccharides from the initial feed were recovered in total permeate. DF did not largely influence FOS retention during NF (it increased from $68.78 \%$ without DF to $70.48 \%$ with DF), but decreased glucose and fructose retentions, from 40.63 to $31.61 \%$ and 25.64 to $18.69 \%$, respectively, which was desirable, allowing greater purification of FOS in the retentate. The yield of total saccharides in the final retentate after combined UF and NF processes was $50.89 \%$ and of FOS was $51.85 \%$, with $19.75 \%$ purity. The results indicate that the combined UF and NF is a promising technique for concentrating yacon saccharides, but more diafiltration steps are required for the improvement of FOS purity.
\end{abstract}

Key words: yacon, fructooligosaccharides, purification, ultrafiltration, nanofiltration

\section{Introduction}

Fructooligosaccharides (FOS) are storage carbohydrates found in some fruits and vegetables that can be considered prebiotics because they reach the colon intact and are selectively fermented by probiotic bacteria like Lactobacillus spp. and Bifidobacterium spp. (1-3). They are linear polydisperse oligomers consisting mainly of $\beta-(2 \rightarrow 1)$ fructosyl-fructose linkages, sometimes containing a starting $\alpha$-D-glucose moiety, that resist hydrolysis by human small intestinal digestive enzymes, which are specific for $\alpha$-glycosidic bonds. They have thus been classified as non- digestible oligosaccharides (4) and are best characterised by their degree of polymerization, between 3 and 10 (1).

FOS, also known as oligofructose, are considered food ingredients and can be used in many food applications as sugar substitutes (5). Besides contributing to a well-balanced diet by increasing the fibre content and the diversity of the fibre sources, FOS specific fermentative characteristics are responsible for numerous health benefits. There are studies relating their consumption to a more balanced composition of intestinal microbiota (6$10)$, improved mineral absorption, especially in post- 
menopausal women (11) and female teenagers (12-14), and endocrine activities (15). There is also evidence supporting improvement of systemic functions, as immune functions $(16,17)$ and lipid homeostasis $(18,19)$, as well as the ability to reduce the risk of various diseases (4).

Oligofructose is industrially produced by partial enzymatic hydrolysis (using an endoinulinase) of inulin extracted from chicory roots or by synthesis from sucrose using fructosyltransferase (5). Studies related to new sources of FOS and production processes could be useful for allowing their application in a wider range of foods. An interesting possibility is their extraction from yacon (Smallanthus sonchifolius) roots, a perennial plant originating from the Andean region, whence it has spread to New Zealand, Japan and Brazil, which differ from other roots by storing carbohydrates in the form of FOS, instead of starch (20).

Yacon roots consist mostly of water, which usually exceeds $80 \%$ of fresh mass, and carbohydrates, rich in FOS, especially 1-kestose (GF2), nystose (GF3) and 1- $\beta$-D-fructofuranosylnystose (GF4). There are also 15-40\% of simple sugars, such as sucrose, fructose and glucose. Other nutrients are reported to be at low concentrations, except for potassium $(20,21)$. It has been reported, however, that the FOS content in yacon tuberous roots significantly decreases during postharvest storage, even at low temperatures $\left(5\right.$ to $\left.10^{\circ} \mathrm{C}\right)(22,23)$. Considering that yacon rootstocks are highly perishable, the development of alternative techniques for extracting, concentrating and purifying yacon FOS would allow their increased consumption by addition to more frequently consumed products, such as yoghurts, cereals and drinks. It would also be possible to reach levels at which a prebiotic effect may occur (5-8 grams per day) (1).

A high selective separation technology is a prerequisite for purity, especially when processing complex plant materials. Membrane technology, currently encompassing mainly ultrafiltration (UF) and nanofiltration (NF), is a potential feasible strategy for industrial manufacture of purified oligosaccharides $(24,25)$. Membrane processes have a number of advantages compared to e.g. chromatographic purification techniques, as they include low energy requirements, hence offer sustainable processing, easy modification of the critical operational variables such as pressure, temperature, feed flow rate and agitation, and relatively easy scale-up (26).

Many authors have obtained good results using ultra- and nanofiltration for purification of oligosaccharides (27-30). Kamada et al. (31) evaluated the effectiveness of combined UF and NF for purifying and concentrating oligosaccharides from yacon rootstock, obtaining a 25-fold concentrated retentate with $98 \%$ of FOS purity. In a similar work, but with chicory rootstock, the NF retentate, in which mono- and disaccharide content was reduced from $9.0 \%$ in the initial solution to $2.6 \%$, was obtained as a $20-$ -fold concentrated product, indicating that the combined membrane-processing system (UF and NF) is quite promising for FOS purification (32). Kamada et al. $(31,32)$, however, did not evaluate the use of diafiltration for FOS purification. They also used freeze-dried yacon rootstock, not fresh ones, in their experiments, which caused additional costs of the process. Kuhn et al. (33) used nanofiltration for purifying FOS present in a mixture of sugars, containing also glucose, fructose and sucrose. Performing diafiltration, they obtained a retentate containing around $80 \%$ of FOS.

In this study, ultra- and nanofiltration were combined to purify fresh yacon root extract, aiming to remove suspended solids and simple sugars as glucose and fructose and concentrate the yacon fructooligosaccharides. The use of NF in combination with discontinuous diafiltration (DF) was also evaluated.

\section{Materials and Methods}

\section{Yacon root extract}

Yacon (Smallanthus sonchifolius) roots were cultivated in São Paulo State, Brazil, and acquired from the Supply Centre of the Rio Grande do Sul State in the city of Porto Alegre, Brazil. The roots were cleaned and selected considering the absence of visible injury and infection, and refrigerated $\left((8 \pm 2){ }^{\circ} \mathrm{C}\right)$ until use for no more than three weeks.

The yacon extract used in the combined ultrafiltration (UF) and nanofiltration (NF) processes was prepared in two steps, adapting the methodology described by Toneli et al. (34). First, yacon roots were sliced and kept for $20 \mathrm{~min}$ in a $0.5 \%$ sodium pyrosulphite (Sigma-Aldrich Brazil, São Paulo, Brazil) solution to minimise the enzymatic browning (35). The roots were ground in a food multiprocessor (Arno, São Paulo, Brazil) and the extracted juice was kept refrigerated. After this, residual saccharides were extracted from ground roots by lixiviation, with the addition of water heated at $80{ }^{\circ} \mathrm{C}$ in the ratio of $2 \mathrm{~kg}$ of water per $1 \mathrm{~kg}$ of ground roots. This mixture was kept at an average temperature of $(80 \pm 2){ }^{\circ} \mathrm{C}$ for $1 \mathrm{~h}$ and then filtered through a 270 -mesh sieve to remove the triturated roots. The two obtained yacon fractions, the juice and the liquid extracted from ground roots, were then filtered and mixed, resulting in the so-called yacon extract. In order to minimise fouling during ultrafiltration, two different filters were used, with 1 and $22 \mu \mathrm{m}$ nominal pore sizes (Parker Filtration, São Paulo, Brazil), which were available in the laboratory.

\section{Membranes}

Three different membranes (two UF and one NF membrane) were tested in a flat sheet module, with $0.00572 \mathrm{~m}^{2}$ area, to select the most adequate one for fructooligosaccharide (FOS) purification. The ultrafiltration membrane, UF-10 and UF-30, were made of polyethersulfone, with nominal molecular mass cut-off (NMMCO) of 10000 and 30000 Da (Synder Filtration, Vacaville, CA, USA), while the nanofiltration membrane, NF-1, with NMMCO of $1000 \mathrm{Da}$, was made of regenerated cellulose (Millipore Indústria e Comércio Ltda., São Paulo, Brazil).

\section{$U F$ and NF equipment}

Experiments were performed in a pilot plant, WGM-KOCH PROTOSEP IV (WGM Sistemas, São Paulo, Brazil), comprising the following equipment: (i) feed tank made of glass with a volume of $1.0 \mathrm{~L}$, (ii) pneumatic 
pump, diaphragm type, model Versa-Matic VM50 (Versa-Matic, Mansfield, TX, USA), operating with compressed air through a system comprising a FLR kit (filter, air regulator and lubricator), (iii) a stainless steel grade 316 housing for the flat sheet module, allowing the installation of membranes with an effective area of $0.00572 \mathrm{~m}^{2}$, (iv) stainless steel grade 316 manometer, with a scale from 0 to 10.5 bar, and $(v)$ valve for pressure control.

\section{Experimental design}

Membranes tested for the separation of saccharides were compressed at 4.5 bar and characterised by their permeate fluxes of water and yacon extract for at least six of the following transmembrane pressures $(\Delta p): 0.75,1.00$, $1.25,1.50,1.75,2.00,2.75,3.00,3.25$ and 3.50 bar. Temperature was kept constant at $(25 \pm 2){ }^{\circ} \mathrm{C}$. The volumetric flux of the permeate $(J p)$ was calculated and expressed in L/ $\left(\mathrm{m}^{2} \cdot \mathrm{h}\right)$. The $\Delta p$ of the procedure was determined by the permeate-flux (Jp) vs. $\Delta p$ curve.

After defining the operating conditions, the yacon extract was processed in two stages, combining UF and NF crossflow processes, according to the methodology described by Kamada et al. (31). Prefiltered yacon extract was subjected to batch UF processing, recirculating the retentate to the feed tank in order to remove large molecules such as proteins and fibres and suspended substances, yielding a saccharide-rich permeate. The UF experiments were performed at a transmembrane pressure of 0.75 bar, recirculation flow of $20 \mathrm{~L} /\left(\mathrm{m}^{2} \cdot \mathrm{h}\right)$ and $25^{\circ} \mathrm{C}$, controlled by water-cooling the feed tank. These operating conditions were determined in previous experiments. UF process was conducted until the initial feed volume was reduced by half.

In the second stage, the clarified saccharide-containing permeate obtained in the UF process was processed by NF, with full recycling of retentate, in order to concentrate the oligosaccharides in the retentate and reduce glucose, fructose, sucrose and salt concentration. This operation was also done together with discontinuous diafiltration (DF), which consisted of adding incremental volumes of distilled water to the retentate aiming to optimise the withdrawal of salts, mono- and disaccharides from the permeate while removing this added volume, and increasing the degree of FOS purification. Every time the permeate volume reached $50 \mathrm{~mL}$, the same volume of water was added to the retentate, totalising $200 \mathrm{~mL}$ of added water. The NF experiments were performed at a transmembrane pressure of 4.5 bar and recirculation flow of approx. 300 $\mathrm{L} / \mathrm{h}$, also determined in previous experiments.

\section{Membrane fouling, cleaning protocol effectiveness and membrane retention}

In all UF and NF experiments, measurements of water flux were carried out before and after filtration to quantify the fouling formation on the membrane. A chemical cleaning procedure was performed at the end of each experiment to restore the flux and retention characteristics of the membrane and prevent the growth of microorganisms in the system. It consisted of rinsing with distilled water, and alkaline, acid and chlorine cleaning, taking into account the membrane $\mathrm{pH}$ and temperature limits.
Fouling was expressed as the percentage difference in water permeate fluxes of the membranes before and after yacon extract ultrafiltration, according to the following equation (36):

$$
\text { Fouling }=\left(\frac{J_{\mathrm{pi}}-J_{\mathrm{pf}}}{J_{\mathrm{pi}}}\right) \cdot 100
$$

where $J_{\mathrm{pi}}$ is water permeate flux of the virgin, unfouled membrane after compaction and before yacon extract UF and $J_{\mathrm{pf}}$ is water permeate flux after yacon extraction by UF and rinsing with water to remove loosely bound foulants, at the same temperature and pressure conditions. The medium fouling value was considered at the different $\Delta p$.

The effectiveness of the ultrafiltration cleaning protocol was measured by calculating the water flux recovery according to the following equation (37):

$$
\text { Flux recovery }=\left(\frac{J_{\mathrm{pc}}}{J_{\mathrm{pi}}}\right) \cdot 100
$$

where $J_{\mathrm{pc}}$ is the water permeate flux after the application of cleaning procedure at the same pressure and temperature as $J_{\mathrm{pi}}$. The medium flux recovery value was considered at the different $\Delta p$.

For each saccharide, the observed retention $\left(R_{\mathrm{obs}}\right)$ was calculated from the following equation, based on the permeate and bulk saccharide concentration, determined from the sample analysis:

$$
R_{\mathrm{obs}}=\left(1-\frac{c_{\mathrm{p}}}{c_{\mathrm{b}}}\right) \cdot 100
$$

where $c_{\mathrm{p}}$ is the permeate concentration and $c_{\mathrm{b}}$ is the bulk concentration of a given saccharide. The retentate was accumulated at the permeate tank until the initial feed volume was reduced by half.

\section{Analytical methods}

The moisture content of fresh yacon rootstock was measured by weighing up and drying samples at $105^{\circ} \mathrm{C}$ until constant mass, according to AOAC method 984.25 (38). The characteristics of yacon extract and of UF and NF feed, retentate and permeate samples were determined by measuring soluble solid content (in ${ }^{\circ}$ Brix), electrical conductivity, $\mathrm{pH}$ and concentration of FOS, glucose and fructose by high-performance liquid chromatography (HPLC). Soluble solid content was determined using a refractometer at $25{ }^{\circ} \mathrm{C}$, according to AOAC method 932.12 (39). The $\mathrm{pH}$ was measured with a Digimed DM20 pH meter (Digimed Instrumentação Analítica, São Paulo, Brazil), following AOAC method 981.12 (40). Electrical conductivity was determined with a Tecnopon mCA150 conductivity meter (MS Tecnopon Equipamentos Especias Ltda., Piracicaba, Brazil).

HPLC analyses were performed adapting the method described by Zuleta and Sambucetti (41) and Fenner Scher et al. (42), using a PerkinElmer series 200 chromatograph equipped with a refractive index detector (HPLC-RI; PerkinElmer Life and Analytical Sciences, Shelton, CT, USA) and Milli-Q water as the mobile phase at $0.6 \mathrm{~mL} /$ min, temperature of $80^{\circ} \mathrm{C}$ and a Phenomenex Rezex RHM 
monosaccharide column, $330 \mathrm{~mm} \times 7.8 \mathrm{~mm}$, with a total run time of $14 \mathrm{~min}$ (Phenomenex Inc., Torrance, CA, USA). The retention times were $6.766 \mathrm{~min}$ for oligofructose, $9.946 \mathrm{~min}$ for glucose and $10.742 \mathrm{~min}$ for fructose. All injections were carried out at least in duplicate. Saccharide content was used for mass balance determination throughout UF and NF process.

\section{Saccharide purity and yield}

The degree of purification (purity) of each saccharide (i) at UF and NF feed, permeate and retentate was calculated according to the following equation (25):

$$
\text { Purity }=\left(\frac{c_{\mathrm{s}}^{\mathrm{i}}}{c_{\mathrm{s}}^{\text {total }}}\right) \cdot 100
$$

where $c_{\mathrm{s}}^{\mathrm{i}}$ is the concentration of saccharide $i$ in a given stream (feed, permeate or retentate) and $c_{\mathrm{s}}^{\text {total }}$ is total saccharide concentration in the same stream. The yield of each saccharide (in $\mathrm{g}$ per $\mathrm{kg}$ of yacon) was calculated using the following equation (25):

$$
\text { Yield }=\frac{m_{\mathrm{s}}^{\mathrm{i}}}{m_{\text {yacon }}}
$$

where $m_{\mathrm{s}}^{\mathrm{i}}$ is the saccharide $i$ mass (in g) in a given stream (feed, permeate or retentate) and $m_{\text {yacon }}$ is yacon root mass (in $\mathrm{kg}$ ) used for preparing the yacon extract for each UF or NF experiment.

\section{Results and Discussion}

\section{Yacon extract characteristics}

The yacon extract characteristics, resulting from the mixture of yacon juice and the liquid extracted from the ground roots by hot water diffusion, are described in Table 1 . The $\mathrm{pH}$ of yacon juice and extract was close to the values found by Fenner Scher et al. (42), who observed the $\mathrm{pH}$ of $(6.09 \pm 0.01)$ when evaluating fresh yacon roots from the same origin as the ones used in this experiment. $\mathrm{Ri}$ beiro (43) has also shown a similar value of 5.87 .

The soluble solid content of the yacon juice was close to that reported by Manrique et al. (44), 8 to $12{ }^{\circ}$ Brix for yacon roots, and a little lower than values found by Fenner Scher et al. (42), $(9.9 \pm 0.01)^{\circ}$ Brix, and by Hermann et al. (45), which varied from 9.9 to $12.6^{\circ}$ Brix. Soluble solids of

Table 1. The $\mathrm{pH}$, soluble solids and saccharide content of yacon juice, liquid extract from ground roots and yacon extract

\begin{tabular}{lrrr}
\hline Parameter & $\begin{array}{c}\text { Yacon } \\
\text { juice }\end{array}$ & $\begin{array}{c}\text { Liquid } \\
\text { from } \\
\text { ground } \\
\text { roots }\end{array}$ & \multicolumn{1}{c}{$\begin{array}{c}\text { Yacon } \\
\text { extract }\end{array}$} \\
\hline $\mathrm{pH}$ & $6.09 \pm 0.07$ & $5.64 \pm 0.03$ & $6.03 \pm 0.07$ \\
Soluble solids/ ${ }^{\circ}$ Brix & $8.50 \pm 0.01$ & $3.42 \pm 0.29$ & $7.50 \pm 0.01$ \\
$w($ FOS $) /($ g per $100 \mathrm{~g} \mathrm{dm})$ & $8.12 \pm 0.06$ & $1.72 \pm 0.01$ & $10.55 \pm 0.02$ \\
$w($ glucose $) /($ g per $100 \mathrm{~g} \mathrm{dm})$ & $14.89 \pm 0.13$ & $2.66 \pm 0.06$ & $17.30 \pm 0.03$ \\
$w($ fructose $) /($ g per $100 \mathrm{~g} \mathrm{dm})$ & $18.52 \pm 0.03$ & $2.91 \pm 0.02$ & $20.60 \pm 0.01$ \\
Yacon root moisture $/ \%$ & $88.16 \pm 0.20$ & & \\
\hline
\end{tabular}

FOS=fructooligosaccharides, $\mathrm{dm}=\mathrm{dry}$ mass yacon extract of $7.5{ }^{\circ}$ Brix were lower due to water dilution with the liquid extracted from yacon ground roots.

The saccharide content of yacon extract, on a dry mass (dm) basis, was: $(10.55 \pm 0.02) \mathrm{g}$ per $100 \mathrm{~g}$ of FOS, $(17.30 \pm 0.03) \mathrm{g}$ per $100 \mathrm{~g}$ of glucose and $(20.60 \pm 0.01) \mathrm{g}$ per $100 \mathrm{~g}$ of fructose. The hot water lixiviated from yacon ground root saccharide added 1.72, 2.66 and $2.91 \mathrm{~g}$ per $100 \mathrm{~g}$ of FOS, glucose and fructose, respectively, to yacon juice, which represented an increase of 21.23, 17.89 and $15.70 \%$ in respective saccharide content.

Fenner Scher et al. (42), evaluating yacon in natura without blanching, found values of (in $\mathrm{g}$ per $100 \mathrm{~g} \mathrm{dm}$ ): $(6.94 \pm 0.04)$ of FOS, $(26.93 \pm 0.03)$ of glucose and $(50.68 \pm 0.1)$ of fructose. Lago et al. (46) obtained values of $(1.07 \pm 0.18)$, $(3.30 \pm 0.28)$ and $(2.99 \pm 0.18) \mathrm{g}$ per $100 \mathrm{~g} \mathrm{dm}$ of FOS, glucose and fructose in yacon juice, respectively, and of $(3.15 \pm$ $0.16),(10.98 \pm 0.32)$ and $(4.30 \pm 0.57) \mathrm{g}$ per $100 \mathrm{~g} \mathrm{dm}$ of FOS, glucose and fructose, respectively, in the pulp (ground roots after juice extraction). Lachman et al. (23) evaluated saccharide content of four yacon ecotypes cultivated in four different years. Considerable differences were observed (on dm basis) in oligofructose (8.0-46.0 g per $100 \mathrm{~g}$ ), glucose (2.04-17.9 g per $100 \mathrm{~g})$ and fructose levels (9.02-43.2 $\mathrm{g}$ per $100 \mathrm{~g}$ ) among ecotypes and cultivation years. A tendency of a decrease of FOS degree of polimerisation (DP) is related to the cultivation of yacon in regions situated more to the north (at $56^{\circ}$ of north latitude no inulin content was observed previously (23)). It was also found that the content of monosaccharides in yacon tubers cultivated in a plastic greenhouse was $37 \%$ higher as compared to the ones cultivated in the field (23). These differences emphasise the difficulty of comparing yacon saccharides among experiments, since there are many factors influencing their content, such as year and method of cultivation and postharvest storage (47). Enzymes related to synthesis and hydrolysis of oligofructose may also be involved, as already described by many authors $(22,48,49)$. Increasing amounts of mono- and disaccharides during storage are also common in the inulin- and FOS-containing roots of chicory (Cichorium intybus L.) and Jerusalem artichoke (Helianthus tuberosus L.) (47).

\section{Ultrafiltration of yacon extract}

The water permeate and yacon extract permeate fluxes trough UF-10 and UF-30 membrans as functions of transmembrane pressure are shown in Fig. 1. The flux of water through both membranes increased linearly with transmembrane pressure, with $\mathrm{R}^{2}=0.998$, confirming that membranes were properly compacted, and the yacon extract permeate flux was significantly smaller than the water permeate flux under the same operating conditions. This indicates that the effect of concentration polarisation is significant for yacon extract and this effect tends to increase at higher transmembrane pressures (TMP). Concentration polarisation occurs when TMP is large enough to transport the solutes with high molecular mass to the membrane surface, limiting the permeation rate by back diffusion of the solute from the membrane surface to the bulk of the feed (50). The accumulation of retained solutes at the upstream surface of the membrane leads to the reduction of effective pressure driving force due to the increase of filtration resistance and also osmotic pressure effects (51). 


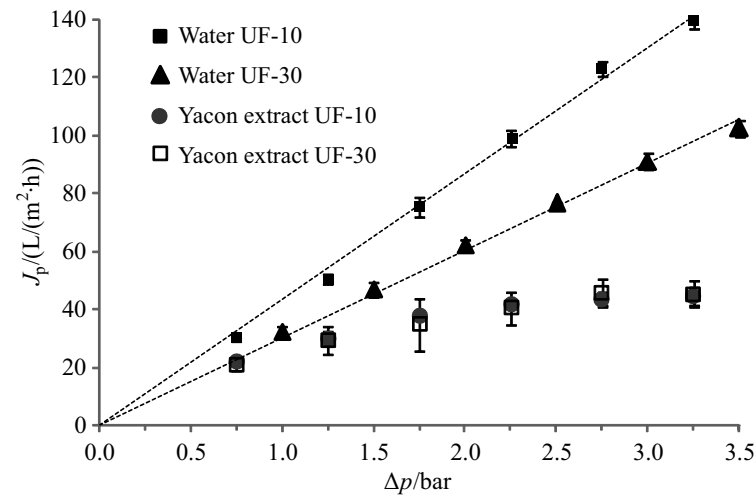

Fig. 1. Water and yacon extract fluxes $v$ s. transmembrane pressure. $1-\mu \mathrm{m}$ pre-filter, temperature $=25^{\circ} \mathrm{C}$. Experiments were done in duplicate

The concentration polarisation cannot be completely avoided, but its extent can be controlled by adjusting the fluid flow characteristics, typically by providing low pressures and high shear rates at the membrane surface, in tangential flow filtration mode $(51,52)$. It was noticed that, under pressures higher than 1.5 bar, yacon extract permeate flux became pressure-independent, indicating that limiting flux was reached. The limiting flux is the maximum flux that can be achieved at steady state in an operation. Yacon extract permeate flux curve was also used to estimate the critical flux, i.e. the maximum possible flux to minimise fouling and concentration polarisation tendency, which was determined by tracing a line from the origin and identifying the point where it became non-linear. Using this method, the chosen transmembrane operating pressure for the ultrafiltration process was 0.75 bar, which provided a recirculation flow of approx. 300 $\mathrm{L} / \mathrm{h}$. It was the highest TMP possible for operating the process under the critical flux and still providing acceptable permeate fluxes.

When using UF-30 membrane, it took approx. 200 min until initial feed volume was reduced by half, while with UF-10 membrane, this volume was reduced in 310 min. Only a slight permeate flux decrease was observed in both membranes during the process: when using UF-10 membrane, it decreased from 15.3 to $13.8 \mathrm{~L} /\left(\mathrm{m}^{2} \cdot \mathrm{h}\right)$ and when using UF-30, from 27.6 to $24.3 \mathrm{~L} /\left(\mathrm{m}^{2} \cdot \mathrm{h}\right)$. Kamada et al. (31) observed larger yacon extract permeate flux decrease, from 42 to $12 \mathrm{~L} /\left(\mathrm{m}^{2} \cdot \mathrm{h}\right)$, during UF with a 20-kDa NMMCO membrane. This may be explained by the higher concentration factor: while the initial volume was reduced by half in this experiment, Kamada et al. (31) reduced the final retentate mass ratio to $3.3 \%$ of the initial feed. Figs. 2 and 3 show water permeate fluxes before $\left(J_{\mathrm{pi}}\right)$ and after ultrafiltration $\left(J_{\mathrm{pf}}\right)$ with UF-10 and UF-30 membranes of yacon extract pretreated by filtration through a $22-\mu \mathrm{m}$ filter.

These water fluxes were used for estimating membrane fouling, a common problem of all types of membrane separation processes that arises from a deposit formation on the external surface of the membrane and/or from adsorption to and within the membrane pores, causing blocking or reduction in effective pore diameter (51). Fouling tendency can be reduced by working below criti-

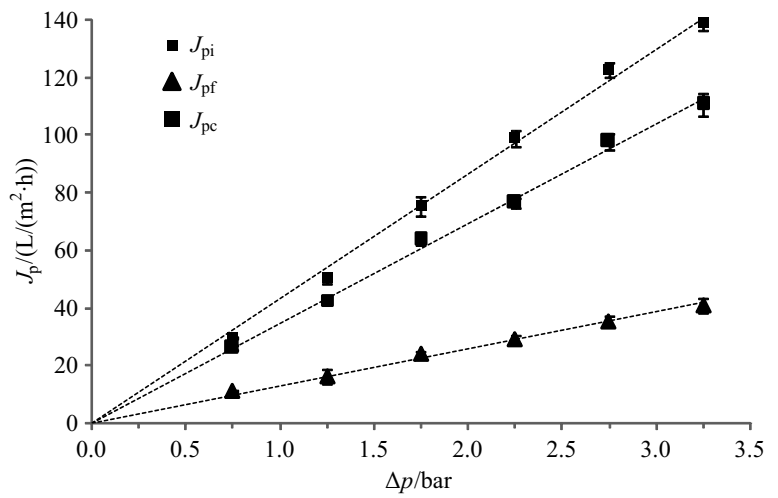

Fig. 2. Water permeate fluxes $\left(J_{\mathrm{p}}\right)$ vs. transmembrane pressure before and after yacon extract ultrafiltration and after cleaning procedure. Membrane UF-10, $22-\mu \mathrm{m}$ prefilter, temperature $=25^{\circ} \mathrm{C}$. Experiments were done in duplicate. $J_{\mathrm{pi}}=$ water permeate flux of virgin, unfouled membrane after compaction; $J_{\mathrm{pf}}=$ water permeate flux after yacon extract ultrafiltration; $J_{\mathrm{pc}}=$ water permeate flux after cleaning procedure

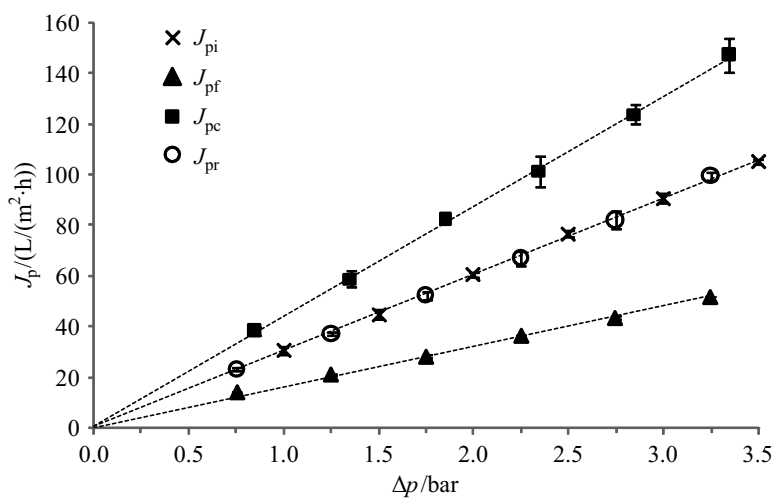

Fig. 3. Water permeate fluxes $\left(J_{\mathrm{p}}\right)$ vs. transmembrane pressure before and after yacon extract ultrafiltration and after cleaning procedure. Membrane UF-30, $22-\mu \mathrm{m}$ prefilter, temperature $=25^{\circ} \mathrm{C}$. Experiments were done in duplicate. $J_{\mathrm{pi}}=$ water permeate flux of virgin, unfouled membrane after compaction; $J_{\mathrm{pf}}=$ water permeate flux after yacon extract ultrafiltration; $J_{\mathrm{pc}}=$ water permeate flux after cleaning procedure; $J_{\mathrm{pr}}=$ water permeate flux after membrane cleaning and recompaction

cal values of flux and pressure, balancing the hydrodynamic force, which drives solutes towards the pores, and the electrostatic forces opposing this motion (53). Figs. 2 and 3 also show water permeate flux after cleaning $\left(J_{p c}\right)$, used for evaluating the cleaning protocol effectiveness.

The optimum prefilter distributes the particles/molecules evenly between the two filters (prefilter and membrane) so they both reach their maximum particle load and the process becomes more efficient. For evaluating the two selected prefilters, membrane fouling formation was calculated for UF-10 and UF-30 membranes, and it was observed that fouling was significantly lower when $1-\mu \mathrm{m}$ prefilter was used, compared to the $22-\mu \mathrm{m}$ prefilter. When using UF-10 membrane, fouling formation was $68.67 \%$ with $22-\mu \mathrm{m}$ prefilter and $26.95 \%$ with $1-\mu \mathrm{m}$ prefilter; when using UF-30 membrane, values of fouling formation for 22- and $1-\mu \mathrm{m}$ prefilter were 52.66 and $16.16 \%$, respectively. This indicates that the $1-\mu \mathrm{m}$ prefilter was more efficient in removing suspended particles that caused 
rapid clogging of membrane pores with yacon extract, which suggests that a feed preclarification is needed. A similar result was obtained by Saha et al. (36), comparing the flux profiles of sugarcane juice and a polysaccharide solution. Both fluxes decreased exponentially, but the multicomponent sugarcane juice feed containing different sizes of macromolecules caused severe fouling (60\%), while with polysaccharides alone, no visible fouling was observed during the experiment.

The cleaning protocol effectiveness was not the same for both membranes. Water flux recovery for UF-10 membrane after cleaning was partial (82.42 \% with $22-\mu \mathrm{m}$ and $81.72 \%$ with 1- $\mu$ m prefilter), but total for UF-30 membrane (133.45 and $139.81 \%$ with 22 - and $1-\mu \mathrm{m}$ prefilter, respectively), which shows that water permeate flux after cleaning increased compared to the flux of the virgin membrane after compaction. This increased flux may have been caused by UF-30 membrane decompaction, because the flux returned to the original values after a new compaction process $\left(J_{\mathrm{pr}}\right)$. Fu et al. (54) noticed that two NF membranes with different properties required different cleaning processes even with the same feed. Song et al. (55) examined membrane cleaning and reported that the tested cleaning agents could not achieve complete flux recovery because some residual foulants were strongly embedded in the concavities of membrane surface. However, Al-Amoudi et al. (53), from the results of the permeability of a fouled NF membrane before and after cleaning, showed that the cleaning process restored the declined flux close to its original value. Al-Amoudi and Lovitt (56) and Liikanen et al. (37) noticed that cleaning, especially alkaline, often increased the flux of the virgin membrane.

Table 2 shows the concentration of fructooligosaccharides, glucose and fructose in the feed, permeate and retentate after ultrafiltration of yacon extract pretreated using 1- $\mu \mathrm{m}$ filter. The observed retention of each saccharide is also presented. Small differences in the initial composition of saccharides were observed between samples due to different dilutions with residual water present in the system. UF was used to clarify yacon extract by removing large molecules, like proteins and other suspended solids, and allowing saccharides of low molecular mass to pass through the membrane pores and to be collected in the

Table 2. Concentration of fructooligosaccharides (FOS), glucose and fructose in the feed, permeate and retentate, and observed retention of saccharides $\left(R_{\mathrm{obs}}\right)$, in the yacon extract obtained with ultrafiltration using UF-10 and UF-30 membranes, with $1-\mu \mathrm{m}$ prefilter

\begin{tabular}{|c|c|c|c|}
\hline Sample & $\frac{\gamma(\mathrm{FOS})}{\mathrm{g} / \mathrm{L}}$ & $\frac{\gamma \text { (glucose })}{\mathrm{g} / \mathrm{L}}$ & $\frac{\gamma(\text { fructose })}{\mathrm{g} / \mathrm{L}}$ \\
\hline UF-10 feed & $9.04 \pm 0.03$ & $18.38 \pm 0.03$ & $23.54 \pm 0.01$ \\
\hline UF-10 permeate & $7.98 \pm 0.07$ & $18.59 \pm 0.02$ & $23.85 \pm 0.01$ \\
\hline UF-10 retentate & $10.28 \pm 0.01$ & $19.64 \pm 0.00$ & $25.40 \pm 0.02$ \\
\hline UF-10 $R_{\mathrm{obs}} / \%$ & 22.35 & 5.36 & 6.10 \\
\hline UF-30 feed & $8.57 \pm 0.59$ & $15.73 \pm 0.44$ & $20.30 \pm 0.05$ \\
\hline UF-30 permeate & $7.42 \pm 0.80$ & $15.51 \pm 0.34$ & $20.21 \pm 0.35$ \\
\hline UF-30 retentate & $8.71 \pm 0.87$ & $15.57 \pm 0.63$ & $20.55 \pm 0.28$ \\
\hline UF-30 $R_{\mathrm{obs}} / \%$ & 14.77 & 0.42 & 1.65 \\
\hline
\end{tabular}

permeate. According to Lachman et al. (21), yacon rootstocks comprise (in \%), in general: moisture 83.1, saccharides 13.8 , ash 1.1, protein 1.0, fibre 0.9 and lipids 0.1 . Both membrane permeates were transparent and colourless, indicating that suspended solids of high molecular mass were probably removed. The observed retention of FOS at the UF-30 membrane $(14.77 \%)$ was smaller than at the UF-10 membrane (22.35\%), as expected due to its higher NMMCO. The same was observed for glucose and fructose.

Ultrafiltration of yacon extract pretreated using 22$-\mu \mathrm{m}$ filter showed significantly higher retentions of saccharides compared to the feed pretreated with $1-\mu \mathrm{m}$ filter, especially with UF-30 membrane. With UF-10 membrane, FOS, glucose and fructose retentions were 27.00, 13.95 and $17.70 \%$ respectively when using $22-\mu \mathrm{m}$ filter, and $22.35,5.36$ and $6.10 \%$ respectively when using $1-\mu \mathrm{m}$ filter. With UF-30 membrane, saccharide retentions with 22- $\mu \mathrm{m}$ prefilter were (in \%): 47.80 of FOS, 18.90 of glucose and 25.14 of fructose; with 1- $\mu \mathrm{m}$ prefilter these retentions were 14.77 of FOS, 0.42 of glucose and 1.65 of fructose. The increase in the observed retentions may have been caused by an incomplete removal of suspended solids by the 22- $\mu \mathrm{m}$ filter, leading to increased concentration polarisation layer and fouling. The increase in retention was more significant for the UF-30 membrane, probably because of the rapid plugging of the larger size pores of this membrane, leading to high fouling (36). These results led to the use of $1-\mu \mathrm{m}$ prefiltered yacon extract in further experiments.

The $\mathrm{pH}$, electrical conductivity and soluble solids were measured at ultrafiltration feed, permeate and retentate. A slight decrease of $\mathrm{pH}$ was observed throughout the process with both membranes, UF-10 (6.11 in feed, 5.95 in permeate and 5.91 in retentate) and UF-30 (6.25, 6.35 and 6.17 in feed, permeate and retentate, respectively). The measurement of electrical conductivity showed a slight increase in the retentate $\left(3.27 \mathrm{mS} / \mathrm{cm}\right.$ at $25^{\circ} \mathrm{C}$ when using UF-10 and $2.46 \mathrm{mS} / \mathrm{cm}$ at $25^{\circ} \mathrm{C}$ with UF-30 membrane), indicating a higher solid content compared to feed (2.93 and $2.37 \mathrm{mS} / \mathrm{cm}$ at $25^{\circ} \mathrm{C}$ with UF-10 and UF-30 membranes, respectively). Soluble solid content was 5.75 and $5.53{ }^{\circ}$ Brix in UF-10 retentate and feed, respectively, and 5.08 and $5.03{ }^{\circ}$ Brix in UF-30 retentate and feed, respectively. Kamada et al. (31) observed an increase in soluble solid content from $2.0^{\circ}$ Brix in the initial feed to 10.9 ${ }^{\circ} \mathrm{Brix}$ in the final retentate during yacon extract ultrafiltration (20-kDa NMMCO membrane). A possible reason for this steep increase in soluble solid content is the higher concentration factor used by these authors, which reduced the final retentate mass ratio to $3.3 \%$ of the initial feed. Considering that high permeate fluxes are desirable for improved process efficiency, and low FOS retentions at this first step of the process yield higher final content of purified FOS, for the nanofiltration experiments only UF-30 permeate was used.

\section{Nanofiltration of the ultrafiltration permeate}

No irreversible fouling occurred during the experiments since there were no differences in the water flux measurements before and after each filtration run and after cleaning. The same result was found by Goulas et al. 
(24) during the nanofiltration of a commercial galactooligosaccharide mixture.

Table 3 shows fructooligosaccharide, glucose and fructose concentrations in nanofiltration feed, permeate and retentate, obtained with and without diafiltration, and their respective observed retentions. Some differences in the initial composition of saccharides were found between samples due to different dilutions with residual water present in the system. Nanofiltration was used to remove salts and mono- and disaccharides, like glucose, fructose and sucrose, concentrating yacon FOS in the retentate. It can be noticed that diafiltration did not influence largely the FOS retention (it increased from $68.78 \%$ without to $70.48 \%$ with diafiltration), but it decreased the retention of glucose and fructose from 40.63 to $31.61 \%$ and from 25.64 to $18.69 \%$, respectively. The lower retention of monosaccharides with diafiltration was highly desirable, allowing a greater purification of FOS at the retentate.

Table 3. Concentration of fructooligosaccharides (FOS), glucose and fructose in the feed, permeate and retentate, and observed retention of saccharides $\left(R_{\mathrm{obs}}\right)$, in the yacon extract obtained with nanofiltration using NF-1 membrane with and without diafiltration

\begin{tabular}{|c|c|c|c|}
\hline Sample & $\frac{\gamma(\mathrm{FOS})}{\mathrm{g} / \mathrm{L}}$ & $\frac{\gamma(\text { glucose })}{\mathrm{g} / \mathrm{L}}$ & $\frac{\gamma(\text { fructose })}{\mathrm{g} / \mathrm{L}}$ \\
\hline \multicolumn{4}{|c|}{ Without diafiltration } \\
\hline Feed & $2.10 \pm 0.03$ & $5.82 \pm 0.02$ & $6.98 \pm 0.02$ \\
\hline Permeate & $0.68 \pm 0.00$ & $3.52 \pm 0.01$ & $5.22 \pm 0.01$ \\
\hline Retentate & $2.19 \pm 0.02$ & $5.92 \pm 0.03$ & $6.70 \pm 0.03$ \\
\hline$R_{\mathrm{obs}} / \%$ & 68.78 & 40.63 & 25.34 \\
\hline \multicolumn{4}{|c|}{ With diafiltration } \\
\hline Feed & $4.84 \pm 0.10$ & $10.37 \pm 0.09$ & $13.07 \pm 0.09$ \\
\hline Permeate & $1.58 \pm 0.06$ & $6.93 \pm 0.13$ & $9.99 \pm 0.12$ \\
\hline Retentate & $5.36 \pm 0.01$ & $10.13 \pm 0.00$ & $12.29 \pm 0.02$ \\
\hline$R_{\mathrm{obs}} / \%$ & 70.48 & 31.61 & 18.69 \\
\hline
\end{tabular}

The observed retention differences of simple sugars and FOS were not as high as desired, especially when using NF without diafiltration, which may partially be explained by the small degree of polymerisation (DP) from yacon oligosaccharides. According to a study by Pedreschi et al. (57), evaluating the selective consumption of yacon saccharides by Bifidobacterium spp. and Lactobacillus spp. probiotic strains, yacon FOS are composed of $27 \%$ of GF2-type fructans, $54 \%$ of GF3 and $19 \%$ of GFn $\geq 4$ molecules; i.e. $81 \%$ of yacon FOS are short oligomers with only two or three fructosyl units polymerised.

Kuhn et al. (33) obtained similar saccharide retentions: 64,28 and $31 \%$ of FOS, glucose and fructose, respectively, during NF of a mixture of sugars containing FOS, glucose, fructose and sucrose with a 1000-Da NMMCO membrane, under 18 bar pressure, at room temperature and without diafiltration. The same authors, with a 300-Da NMMCO membrane, obtained retentions of 66, 18 and $15 \%$ of FOS, glucose and fructose respectively. Kamada et al. (31) calculated retentions of $14.0 \%$ of mono- saccharides, $46.2 \%$ of disaccharides, $80.9 \%$ of trisaccharides and 91.5 to $99.9 \%$ of saccharides of $\mathrm{DP}=4$ and higher, with a 1000-Da NMMCO membrane at 50 bar during nanofiltration of a saccharide mixture from yacon roots previously clarified by UF (20-kDa NMMCO membrane). Using a 500-Da NMMCO membrane, they achieved respective retentions of $64.9,81.6,97.3$ and 99.2 to $99.9 \%$. Moreno-Vilet et al. (58) studied nanofiltration for separating inulin-type fructans from model solutions containing low molecular mass sugars (sucrose, glucose and fructose) using a pilot cross-flow unit. They found inulin retention values over $90 \%$ with a $600-\mathrm{Da}$ NMMCO membrane at 14 bar. Goulas et al. (24) observed retentions of 71,45 and $11 \%$ of raffinose, sucrose and fructose, respectively, during nanofiltration with a 1000-Da NMMCO membrane at 6.9 bar.

It is known that the fractionation of saccharides and oligosaccharides by nanofiltration depends on several factors: membrane pore size distribution, filtration pressure and temperature, solute concentration and $\mathrm{pH}$ $(28,29)$. Goulas et al. $(24)$ reported increasing retentions of saccharides, especially monosaccharides, as pressure was increased from 6.9 to $27.6 \mathrm{bar}$, due to increased solvent flux and membrane compaction. The same authors also observed that an increase in temperature from 25 to $60^{\circ} \mathrm{C}$ decreased retentions due to reduced viscosity and increased diffusion. The size of a monosaccharide is equal to or smaller than the cut-off sizes of the NF membranes. The calculated diameters of the monosaccharide molecules are approx. $0.6-0.8 \mathrm{~nm}$ and the reported measured pore diameters of the common commercial NF membranes are from 0.6 to $2.0 \mathrm{~nm}$, including the mean pore diameter of approx. $0.8-0.9 \mathrm{~nm}$. Thus, the comparatively small monosaccharides are the most affected when the total permeate flux changes due to the changes in pressure or temperature (29). This means that higher pressures may promote an undesirable increase in monosaccharide retention, while higher temperatures apparently decrease retentions, which may be interesting for glucose and fructose, but not for FOS.

The influence of $\mathrm{pH}$ on the nanofiltration of saccharides was studied by Himstedt et al. (59), who evaluated the effect of $\mathrm{pH}$ on the separation of monosaccharides, disaccharides and their mixtures using membranes whose surface was modified by grafting poly(acrylic acid) (PAA) nanochains applying a UV-initiated free radical polymerisation method. They observed that $\mathrm{pH}$ dramatically affected membrane flux, rejection and selectivity, probably due to different interactions between the sugar molecules and the neutral PAA chain or its negative conjugate; other possible explanation is conformational changes of the grafted surface layer due to protonation and deprotonation of the acid groups on the polymer chains. Simulations conducted by the same authors to investigate the specific interactions between glucose/sucrose and the neutral/negatively charged PAA chains showed that both sugar size and PAA charge affect significantly the sugar-polymer interactions.

Another factor influencing nanofiltration is membrane material and pore size distribution. Goulas et al. (24) and Kuhn et al. (33) observed that membranes composed of polyethersulfone (less hydrophilic) appear to ex- 
ert better separation of saccharides than cellulose (more hydrophilic) membranes, as the one used in this experiment. Also, according to these authors, the small molecular size difference among FOS, glucose and fructose requires the use of membranes with a more uniform pore size distribution.

Van der Bruggen et al. (60) affirm that nanofiltration membranes for uncharged solutes are characterised by a sigmoidal rejection curve as a function of molar mass, which results in an insufficient separation of different compounds on the basis of molecular size, as it is very difficult to retain one component completely and at the same time allow a second component, slightly different in size or charge, to pass completely. The same authors suggest that the use of integrated continuous countercurrent recycle membrane cascades, in analogy with (conventional) separations based on thermodynamic equilibrium, may allow better separations between individual compounds, or fractionation of a mixture.

A slight decrease in $\mathrm{pH}$ could also be observed throughout both nanofiltration processes: 7.09 in feed, 6.75 in permeate and 6.70 in retentate (NF without diafiltration) and $6.00,5.74$ and 5.50 in feed, permeate and retentate, respectively (NF with diafiltration). Electrical conductivity showed a slight increase in the retentate obtained with $\mathrm{NF}$ without diafiltration (from $0.78 \mathrm{mS} / \mathrm{cm}$ at $25^{\circ} \mathrm{C}$ in feed to $0.81 \mathrm{mS} / \mathrm{cm}$ at $25{ }^{\circ} \mathrm{C}$ in retentate) and a decrease in the retentate obtained with the diafiltration NF (from 1.52 to $1.45 \mathrm{mS} / \mathrm{cm}$ at $25^{\circ} \mathrm{C}$ in feed and retentate, respectively) because of the addition of distilled water. There was no significant difference between soluble solid content in feed and retentate fractions in both experiments.

\section{Mass balance}

The mass balance throughout the UF and NF processes, with and without diafiltration, is shown in Table 4. After UF with diafiltration, $63.75 \%$ of the saccharides from the initial feed were recovered in the total permeate. Yield of saccharides in the NF final retentate obtained with combined UF and NF processes associated with diafiltration of total saccharides was calculated to be $50.89 \%$ and of FOS $51.85 \%$. Increased saccharide yields in the diafiltration experiments occurred due to a higher overall initial concentration of saccharides. As previously explained, these differences in initial composition of saccharides between samples were caused by different dilutions with residual water present in the system. Kamada et al. (31), using combined UF and NF processes, were able to recover 82.2 and $56.4 \%$ of the initial saccharides in the UF permeate (20-kDa NMMCO membrane) and NF retentate (1000-Da NMMCO membrane), respectively.

Analysing the nanofiltration retentate purity data, it can be noticed that the enrichment in FOS vs. simple sugars was not as high as desirable. A possible reason is that FOS, glucose and fructose molecules have similar sizes and the membrane has a pore size distribution which does not allow effective fractionation of these molecules. The diafiltration process, nevertheless, allowed a slight FOS purification with a purity increase from 17.44 to $19.75 \%$. These results may suggest that the retentions of

Table 4. Mass balance throughout the ultrafiltration and nanofiltration processes, with and without diafiltration, in feed, permeate and retentate fractions

\begin{tabular}{|c|c|c|c|c|c|c|c|c|c|c|}
\hline & & \multicolumn{3}{|c|}{ Feed } & \multicolumn{3}{|c|}{ Permeate } & \multicolumn{3}{|c|}{ Retentate } \\
\hline & & $\mathrm{m} / \mathrm{g}$ & Purity/\% & $\frac{\text { Yield }}{\mathrm{g} / \mathrm{kg}}$ & $\mathrm{m} / \mathrm{g}$ & Purity/\% & $\frac{\text { Yield }}{\mathrm{g} / \mathrm{kg}}$ & $\mathrm{m} / \mathrm{g}$ & Purity/\% & $\frac{\text { Yield }}{\mathrm{g} / \mathrm{kg}}$ \\
\hline \multicolumn{11}{|c|}{ Without diafiltration } \\
\hline \multirow{4}{*}{ UF-30 } & FOS & 11.59 & 21.78 & 12.50 & 3.43 & 16.10 & 3.69 & 7.46 & 24.06 & 8.04 \\
\hline & Glucose & 19.01 & 35.71 & 20.50 & 7.63 & 35.85 & 8.23 & 11.08 & 35.72 & 11.94 \\
\hline & Fructose & 22.63 & 42.51 & 24.40 & 10.23 & 48.05 & 11.03 & 12.47 & 40.22 & 13.45 \\
\hline & Total & 53.23 & 100.00 & 57.39 & 21.29 & 100.00 & 22.95 & 31.01 & 100.00 & 33.43 \\
\hline \multirow{4}{*}{ NF-1 } & FOS & 3.43 & 16.10 & 3.69 & 0.13 & 7.24 & 0.14 & 3.14 & 16.85 & 3.38 \\
\hline & Glucose & 7.63 & 35.85 & 8.23 & 0.69 & 37.32 & 0.74 & 6.61 & 35.47 & 7.12 \\
\hline & Fructose & 10.23 & 48.05 & 11.03 & 1.02 & 55.44 & 1.10 & 8.88 & 47.68 & 9.58 \\
\hline & Total & 21.29 & 100.00 & 22.95 & 1.84 & 100.00 & 1.98 & 18.63 & 100.00 & 20.08 \\
\hline \multicolumn{11}{|c|}{ With diafiltration } \\
\hline \multirow{4}{*}{ UF-30 } & FOS & 15.31 & 19.38 & 10.79 & 8.78 & 17.44 & 6.19 & 4.92 & 19.69 & 3.47 \\
\hline & Glucose & 28.50 & 36.08 & 20.09 & 18.57 & 36.87 & 13.09 & 8.90 & 35.62 & 6.27 \\
\hline & Fructose & 35.18 & 44.54 & 24.80 & 23.00 & 45.69 & 16.22 & 11.16 & 44.69 & 7.87 \\
\hline & Total & 78.98 & 100.00 & 57.68 & 50.35 & 100.00 & 35.50 & 24.98 & 100.00 & 17.21 \\
\hline \multirow{4}{*}{ NF-1 } & FOS & 8.78 & 17.44 & 6.19 & 0.85 & 8.55 & 0.60 & 7.94 & 19.75 & 5.60 \\
\hline & Glucose & 18.57 & 36.87 & 13.09 & 3.71 & 37.44 & 2.61 & 14.74 & 36.66 & 10.39 \\
\hline & Fructose & 23.00 & 45.69 & 16.22 & 5.35 & 54.01 & 3.77 & 17.52 & 43.59 & 12.35 \\
\hline & Total & 50.35 & 100.00 & 35.50 & 9.90 & 100.00 & 6.98 & 40.19 & 100.00 & 28.33 \\
\hline
\end{tabular}

Yield is expressed in g per kg of yacon roots 
glucose and fructose are FOS concentration-dependent, but these have not been experimentally evaluated. Since glucose and fructose retentions (31.6 and $18.69 \%$ ) at the diafiltration process were smaller than FOS retention $(70.48 \%)$, as discussed previously, we suggest that further distilled water additions with increased permeate volume removal could be evaluated, as it may lead to improved glucose and fructose withdrawal and, consequently, higher FOS purity.

The obtained final nanofiltration retentate, even not consisting of pure FOS, may still be applied as a functional ingredient in non-dietetic foods (because of the presence of simple sugars). Gullón et al. (61) evaluated the prebiotic potential of xylooligosaccharide (XOS) concentrates purified by membrane technology from malting industry solid waste, assessing the effect of different purity and/or molecular mass distribution. They concluded that purity of XOS concentrates did not play a significant role in fermentation, whereas the sample with shorter average degree of polymerisation presented faster fermentation kinetics and led to the highest concentration of lactic acid.

\section{Conclusions}

After UF, a large fraction of the saccharides in the initial feed was recovered in the total permeate. Saccharide yields in the final NF retentate after the combined UF and NF processes were acceptable, but FOS purity was not as high as desired. Diafiltration did not influence largely FOS retention in NF, but it decreased glucose and fructose retentions, which was the aim, allowing greater purification of FOS at the retentate. The combined UF and NF is promising for concentrating yacon saccharides, but it did not totally purify FOS, suggesting that more diafiltration steps are required to improve the preferential removal of mono- and disaccharides while retaining and concentrating saccharides of higher DP in the retentate.

\section{Acknowledgements}

The authors thank the CNPq (National Counsel of Technological and Scientific Development) and the Research Foundation of the State of Rio Grande do Sul (FAPERGS), Brazil, for financial support.

\section{References}

1. Kolida S, Gibson GR. Prebiotic capacity of inulin-type fructans, J Nutr. 2007;137:S2503-6.

2. Jenkins DJA, Kendall CWC, Vuksan V. Inulin, oligofructose and intestinal function. J Nutr. 1999;129:1431.

3. Tuohy KM, Kolida S, Lustenberger AM, Gibson GR. The prebiotic effects of biscuits containing partially hydrolysed guar gum and fructo-oligosaccharides - a human volunteer study. Br J Nutr. 2001;86:341-8. http://dx.doi.org/10.1079/BJN2001394

4. Roberfroid MB. Inulin-type fructans: functional food ingredients. J Nutr. 2007;137:S2493-502.

5. Franck A. Technological functionality of inulin and oligofructose. Br J Nutr. 2002;87:S287-91. http://dx.doi.org/10.1079/BJN/2002550

6. Rao VA. The prebiotic properties of oligofructose at low intake levels. Nutr Res. 2001;21:843-8. http://dx.doi.org/10.1016/S0271-5317(01)00284-6
7. Menne E, Guggenbuhl N. Fn-type chicory inulin hydrolysate has a prebiotic effect in humans. J Nutr. 2000;130:1197-9.

8. Guigoz Y, Rochat F, Perruisseau-Carrier G, Rochat I, Schiffrin EJ. Effects of oligosaccharide on the faecal flora and nonspecific immune system in elderly people. Nutr Res. 2002;22: 13-25.

http://dx.doi.org/10.1016/S0271-5317(01)00354-2

9. Waligora-Dupriet AJ, Campeotto F, Nicolis I, Bonet A, Soulaines P, Dupont C, et al. Effect of oligofructose supplementation on gut microflora and well-being in young children attending a day care centre. Int J Food Microbiol. 2007;113: 108-13. http://dx.doi.org/10.1097/MPG.0b013e318164d920

10. Veereman G. Pediatric applications of inulin and oligofructose. J Nutr. 2007;137:S2585-9.

11. Holloway L, Moynihan S, Abrams SA, Kent K, Hsu AR, Friedlander AL. Effects of oligofructose-enriched inulin on intestinal absorption of calcium and magnesium and bone turnover markers in postmenopausal women. Br J Nutr. 2007;97:365-72. http://dx.doi.org/10.1017/S000711450733674X

12. Griffin IJ, Davila PM, Abrams SA. Non-digestible oligosaccharides and calcium absorption in girls with adequate calcium intakes. Br J Nutr. 2002;87:S187-91. http://dx.doi.org/10.1079/BJN/2002536

13. Griffin IJ, Hicks PMD, Heaney RP, Abrams SA. Enriched chicory inulin increases calcium absorption mainly in girls with lower calcium absorption. Nutr Res. 2003;23:901-9. http://dx.doi.org/10.1016/S0271-5317(03)00085-X

14. de Souza MCC, Lajolo FM, de Araujo Martini L, Correa NB, Dan MC, Wensel de Menezes E. Effect of oligofructose-enriched inulin on bone metabolism in girls with low calcium intakes. Braz Arch Biol Technol. 2010;53:193-201. http://dx.doi.org/10.1590/S1516-89132010000100024

15. Delzenne NM, Cani PD, Daubioul C, Neyrinck AM. Impact of inulin and oligofructose on gastrointestinal peptides. Br J Nutr. 2005;93:S157-61. http://dx.doi.org/10.1079/BJN20041342

16. Seifert $S$, Watzl B. Inulin and oligofructose: review of experimental data on immune modulation. J Nutr. 2007;137:S2563-7.

17. Watzl B, Girrbach S, Roller M. Inulin, oligofructose and immunomodulation. Br J Nutr. 2005;93:S49-55. http://dx.doi.org/10.1079/BJN20041357

18. Delzenne NM, Daubioul C, Neyrinck A, Lasa M, Taper HS. Inulin and oligofructose modulate lipid metabolism in animals: review of biochemical events and future prospects. Br J Nutr. 2002;87:S255-9. http://dx.doi.org/10.1079/BJN/2002545

19. Letexier D, Diraison F, Beylot M. Addition of inulin to a moderately high-carbohydrate diet reduces hepatic lipogenesis and plasma triacylglycerol concentrations in humans. Am J Clin Nutr. 2003;77:559-64.

20. Ojansivu I, Ferreira CL, Salminen S. Yacon, a new source of prebiotic oligosaccharides with a history of safe use. Trends Food Sci Technol. 2011;22:40-6. http://dx.doi.org/10.1016/j.tifs.2010.11.005

21. Lachman J, Fernandez EC, Orsak M. Yacon Smallanthus sonchifolia (Poepp. et Endl.) H. Robinson chemical composition and use - a review. Plant Soil Environ. 2003;49:283-90.

22. Narai-Kanayama A, Tokita N, Aso K. Dependence of fructooligosaccharide content on activity of fructooligosaccharidemetabolizing enzymes in yacon (Smallanthus sonchifolius) tuberous roots during storage. J Food Sci. 2007;72:S381-7. http://dx.doi.org/10.1111/j.1750-3841.2007.00422.x

23. Lachman J, Havrland B, Fernández EC, Dudjak J. Saccharides of yacon [Smallanthus sonchifolius (Poepp. et Endl.) H. Robinson] tubers and rhizomes and factors affecting their content. Plant Soil Environ. 2004;50:383-90. 
24. Goulas AK, Kapasakalidis PG, Sinclair HR, Rastall RA, Grandison AS. Purification of oligosaccharides by nanofiltration. J Membr Sci. 2002;209:321-35. http://dx.doi.org/10.1016/S0376-7388(02)00362-9

25. Kuhn RC, Maugeri Filho F, Silva V, Palacio L, Hernandez A, Pradanos P. Mass transfer and transport during purification of fructooligosaccharides by nanofiltration. J Membr Sci. 2010;365:356-65.

http://dx.doi.org/10.1016/j.memsci.2010.09.031

26. Pinelo M, Jonsson G, Meyer AS. Membrane technology for purification of enzymatically produced oligosaccharides: Molecular and operational features affecting performance. Sep Purif Technol. 2009;70:1-11. http://dx.doi.org/10.1016/j.seppur.2009.08.010

27. Catarino I, Minhalma M, Beal LL, Mateus M, de Pinho MN. Assessment of saccharide fractionation by ultrafiltration and nanofiltration. J Membr Sci. 2008;312:34-40. http://dx.doi.org/1016/j.memsci.2007.12.057

28. Minhalma M, Beal LL, Catarino I, Mateus M, de Pinho MN. Optimization of saccharide fractionation using nanofiltration/ultrafiltration. Desalination. 2006;199:337-9. http://dx.doi.org/10.1016/j.desal.2006.03.079

29. Sjöman E, Mänttäri M, Nyström M, Koivikko H, Heikkilä H. Separation of xylose from glucose by nanofiltration from concentrated monosaccharide solutions. J Membr Sci. 2007; 292:106-15. http://dx.doi.org/10.1016/j.memsci.2007.01.019

30. Nabarlatz D, Torras C, Garcia-Valls R, Montané D. Purification of xylo-oligosaccharides from almond shells by ultrafiltration. Sep Purif Technol. 2007;53:235-43. http://dx.doi.org/10.1016/j.seppur.2006.07.006

31. Kamada T, Nakajima M, Nabetani H, Iwamoto S. Pilot-scale study of the purification and concentration of non-digestible saccharides from yacon rootstock using membrane technology. Food Sci Technol Res. 2002;8:172-7. http://dx.doi.org/10.3136/fstr.8.172

32. Kamada T, Nakajima M, Nabetani H, Saglam N, Iwamoto S. Availability of membrane technology for purifying and concentrating oligosaccharides. Eur Food Res Technol. 2002;214: $435-40$. http://dx.doi.org/10.1007/s00217-001-0486-6

33. Kuhn RC, Palacio L, Pradanos P, Hernandez A, Maugeri Filho F. Selection of membranes for purification of fructooligosaccharides. Desalination Water Treat. 2011;27:18-24. http://dx.doi.org/10.5004/dwt.2011.2038

34. Toneli JTCL, Mürr FEX, Martinelli P, Dal Fabbro IM, Park KJ. Optimization of a physical concentration process for inulin. J Food Eng. 2007;80:832-8. http://dx.doi.org/10.1016/j.jfoodeng.2006.07.012

35. Padilha VM, Rolim PM, Salgado SM, Livera AVS, Oliveira MGd. Evaluation of yacon (Smallanthus sonchifolius) drying time and oxi-redutase acxtivity under chemical treatment. Ciência Rural. 2009;39:2178-84 (in Portuguese).

36. Saha NK, Balakrishnan M, Ulbricht M. Sugarcane juice ultrafiltration: FTIR and SEM analysis of polysaccharide fouling. J Membr Sci. 2007;306:287-97. http://dx.doi.org/10.1016/j.memsci.2007.09.006

37. Liikanen R, Yli-Kuivila J, Laukkanen R. Efficiency of various chemical cleanings for nanofiltration membrane fouled by conventionally-treated surface water. J Membr Sci. 2002;195: 265-76. http://dx.doi.org/10.1016/S0376-7388(01)00569-5

38. AOAC Official Method 984.25. Moisture (loss of mass on drying) in frozen french-fried potatoes. Arlington, USA: AOAC International; 1984.

39. AOAC Official Method 932.12. Solids (soluble) in fruits and fruit products. Arlington, USA: AOAC International; 2000.
40. AOAC Official Method 981.12. $\mathrm{pH}$ of acidified foods. Arlington, USA: AOAC International; 2000.

41. Zuleta A, Sambucetti ME. Inulin determination for food labeling. J Agric Food Chem. 2001;49:4570-2. http://dx.doi.org/10.1021/jf010505o

42. Fenner Scher C, de Oliveira Rios A, Pelayo Zapata Noreña C. Hot air drying of yacon (Smallanthus sonchifolius) and its effect on sugar concentrations. Int J Food Sci Technol. 2009; 44:2169-75.

http://dx.doi.org/10.1111/j.1365-2621.2009.02056.x

43. Ribeiro JA. Chemical and biochemical studies of in natura and processed yacon (Smallanthus sonchifolius) and its consume influence on rats glycemic levels and fecal lipids [PhD Thesis]. Lavras, Brazil: Federal University of Lavras; 2008. (in Portuguese).

44. Manrique I, Párraga A, Hermann M. Yacon syrup: principles and processing. Lima, Peru: International Potato Center; 2005. p. 31.

http://cipotato.org/wp-content/uploads/2014/07/1919-Yacon_ Syrup.pdf

45. Hermann M, Freire I, Pazos C. Compositional diversity of the yacon storage root. In: Impact on a Changing World. Program Report 1997-1998. Lima, Peru: International Potato Center; 1999.

http://www2.cipotato.org/publications/program_reports/ 97_98/51yacon.pdf

46. Lago C, Bernstein A, Brandelli A, Noreña CZP. Characterization of powdered yacon (Smallanthus sonchifolius) juice and pulp. Food Bioprocess Technol. 2011;4:1-9. http://dx.doi.org/10.1007/s11947-011-0617-4

47. Graefe S, Hermann M, Manrique I, Golombek S, Buerkert A. Effects of post-harvest treatments on the carbohydrate composition of yacon roots in the Peruvian Andes. Field Crops Res. 2004;86:157-65. http://dx.doi.org/10.1016/j.fcr.2003.08.003

48. Fukai K, Miyazaki S, Nanjo F, Hara Y. Distribution of carbohydrates and related enzyme-activities in yacon (Polymniasonchifolia). Soil Sci Plant Nutr. 1993;39:567-71. http://dx.doi.org/10.1080/00380768.1993.10419797

49. Fukai K, Ohno S, Goto K, Nanjo F, Hara Y. Seasonal fluctuations in fructan content and related enzyme activities in yacon (Polymnia sonchifolia). Soil Sci Plant Nutr. 1997;43:1717. http://dx.doi.org/10.1080/00380768.1997.10414725

50. Yazdanshenas M, Tabatabaee-Nezhad SAR, Soltanieh M, Roostaazad R, Khoshfetrat AB. Contribution of fouling and gel polarization during ultrafiltration of raw apple juice at industrial scale. Desalination. 2010;258:194-200. http://dx.doi.org/10.1016/j.desal.2010.03.014

51. van Reis R, Zydney A. Bioprocess membrane technology. J Membr Sci. 2007;297:16-50.

http://dx.doi.org/10.1016/j.memsci.2007.02.045

52. Bacchin P, Aimar P, Field RW. Critical and sustainable fluxes: Theory, experiments and applications. J Membr Sci. 2006;281: 42-69. http://dx.doi.org/10.1016/j.memsci.2006.04.014

53. Al-Amoudi A, Williams P, Mandale S, Lovitt RW. Cleaning results of new and fouled nanofiltration membrane characterized by zeta potential and permeability. Sep Purif Technol. 2007;54:234-40. http://dx.doi.org/10.1016/j.seppur.2006.09.014

54. Fu P, Ruiz H, Lozier J, Thompson K, Spangenberg C. A pilotstudy on groundwater natural organics removal by low-pressure membranes. Desalination. 1995;102:47-56. http://dx.doi.org/10.1016/0011-9164(95)00040-9

55. Song W, Ravindran V, Koel BE, Pirbazari M. Nanofiltration of natural organic matter with $\mathrm{H}_{2} \mathrm{O}_{2} / \mathrm{UV}$ pretreatment: foul- 
ing mitigation and membrane surface characterization. J Membr Sci. 2004;241:143-60. http://dx.doi.org/10.1016/j.memsci.2004.04.034

56. Al-Amoudi A, Lovitt RW. Fouling strategies and the cleaning system of NF membranes and factors affecting cleaning efficiency. J Membr Sci. 2007;303:6-28.

http://dx.doi.org/10.1016/j.memsci.2007.06.002

57. Pedreschi R, Campos D, Noratto G, Chirinos R, CisnerosZevallos L. Andean yacon root (Smallanthus sonchifolius Poepp. Endl) fructooligosaccharides as a potential novel source of prebiotics. J Agric Food Chem. 2003;51:5278-84. http://dx.doi.org/10.1021/jf0344744

58. Moreno-Vilet L, Bonnin-Paris J, Bostyn S, Ruiz-Cabrera MA, Moscosa-Santillán M. Assessment of sugars separation from a model carbohydrates solution by nanofiltration using a de- sign of experiments (DoE) methodology. Sep Purif Technol. 2014;131:84-93.

http://dx.doi.org/10.1016/j.seppur.2014.04.040

59. Himstedt HH, Du H, Marshall KM, Wickramasinghe SR, Qia $\mathrm{X} . \mathrm{pH}$ responsive nanofiltration membranes for sugar separations. Ind Eng Chem Res. 2013;52:9259-69. http://dx.doi.org/10.1021/ie400982p

60. Van der Bruggen B, Manttari M, Nystrom N. Drawbacks of applying nanofiltration and how to avoid them: A review. Sep Purif Technol. 2008;63:251-63. http://dx.doi.org/10.1016/j.seppur.2008.05.010

61. Gullón P, González-Muñoz MJ, Parajó JC. Manufacture and prebiotic potential of oligosaccharides derived from industrial solid wastes. Bioresour Technol. 2011;102:6112-9. http://dx.doi.org/10.1016/j.biortech.2011.02.059 